\title{
L'IFHA inaugure ses nouveaux locaux sur le campus Westend
}

Pierre Monnet

\section{(2) OpenEdition \\ 1 Journals}

Édition électronique

URL : http://journals.openedition.org/ifha/7408

DOI : 10.4000/ifha.7408

ISSN : 2198-8943

\section{Éditeur}

IFRA - Institut franco-allemand (sciences historiques et sociales)

\section{Édition imprimée}

Date de publication : 1 décembre 2013

ISSN : 2190-0078

\section{Référence électronique}

Pierre Monnet, "L'IFHA inaugure ses nouveaux locaux sur le campus Westend », Revue de l'IFHA [En ligne], 5 | 2013, mis en ligne le 17 février 2014, consulté le 15 septembre 2020. URL : http://

journals.openedition.org/ifha/7408

Ce document a été généré automatiquement le 15 septembre 2020.

(CIFHA 


\title{
L'IFHA inaugure ses nouveaux locaux sur le campus Westend
}

\author{
Pierre Monnet
}

1 Le 19 avril 2013, l'IFHA a inauguré de manière festive les nouveaux locaux que son université partenaire d'accueil, la Johann-Wolfgang Goethe Universität de Francfort, met à sa disposition conformément aux termes de la convention liant les deux institutions signée en 2009.

2 De son arrivée à Francfort en 2009 jusqu'en mars 2013, l'IFHA a d'abord été hébergée dans les bâtiments du campus originel de l'université (fondée en octobre 1914 et proche donc de la célébration de son centenaire en 2014) situés dans le quartier de Bockenheim, plus précisément dans le Jügel-Haus (du nom du libraire francfortois Carl Christian Jügel), vaste corps néobaroque construit en 1906 à proximité du Musée Senckenberg, le deuxième plus grand musée d'histoire naturelle d'Allemagne (du nom de Johann Christian Senckenberg, 1707-1772, botaniste et créateur de la fondation du même nom en 1763).

3 Depuis 2001, les facultés présentes sur le campus Bockenheim ont progressivement déménagé sur le nouveau campus Westend accueillant l'ensemble des départements des lettres, sciences économiques, sociales et juridiques (en dehors du campus Riedberg accueillant les sciences naturelles et du campus médical situé à Sachsenhausen autour de l'hôpital universitaire). L'IFHA a fait partie de la dernière tranche des laboratoires et facultés transportés d'un campus à l'autre, l'aire délaissée de Bockenheim étant appelée à devenir à partir de 2017 un campus culturel regroupant le conservatoire de musique, un théâtre, de la danse, des ateliers d'artistes...

4 Après son déménagement en mars 2013, l'IFHA a donc rejoint le nouveau campus érigé autour du vaste bâtiment central intitulé «IG-Farben Haus ", élevé de 1928 à 1931 sur l'emplacement d'un vaste parc qui avait appartenu au XIXe siècle à la branche francfortoise des Rothschild.

5 Cet IG-Farben-Haus fut construit par l'architecte Hans Pöelzig (1869-1936), l'un des protagonistes du nouveau style architectural du Bauhaus dans les années 1920, pour servir de siège social à l'entreprise chimique IG-Farben fondée en 1925, dont les activités 
pendant le régime nazi furent liées à la production industrielle de guerre, de caoutchouc synthétique (notamment autour des usines Buna du complexe d'Auschwitz) et de gaz mortels (parmi lesquels le Zykon B employé dans les chambres d'extermination des camps de concentration). À ce titre, le groupe fut démantelé, et son siège social demeuré intact malgré les bombardements qui rasèrent Francfort en 1944, servit en 1945 à abriter le quartier général des forces alliées américaines en Europe avec le général Eisenhower qui y établit son siège (il y demeura lui-même jusqu'en 1948). C'est ici que fut proclamée la constitution du Land de Hesse, que furent accomplies les étapes préparatoires à la constitution fédérale allemande et que fut conçue la naissance du D-mark. Après la réunification allemande, le bâtiment est restitué au Land de Hesse en 1995 qui le destine à accueillir l'université des SHS après une rénovation complète achevée en 2001.

C'est donc au cœur de ce bâtiment chargé d'une histoire complexe reliant la bourgeoise juive de Francfort, l'innovation culturelle de Weimar, les exactions nazies, l'occupation américaine et la réunification allemande, que l'IFHA, dédié justement à la recherche historique entre les deux pays, a reçu six bureaux attenants au cinquième étage de ce vaisseau architectural de 250 mètres de longueur sur 35 mètres de hauteur, directement à côté du Fritz-Bauer Institut, le centre de documentation consacré à l'histoire de l'holocauste. Cette situation nouvelle, qui place l'IFHA au contact direct des départements de lettres, d'histoire, de sociologie, d'archéologie et de philosophie avec lesquels il collabore régulièrement, établit également le centre à proximité du cluster d'excellence de l'université consacré à la production des ordres normatifs, de la Bibliothèque SHS de l'université bientôt renforcée par la venue prochaine de la bibliothèque universitaire, de la Bibliothèque Nationale allemande et des nouveaux bâtiments de l'Institut Max-Planck d'histoire européenne du droit, désormais logé sur le campus et riche d'un fonds de 480.000 ouvrages en histoire juridique.

7 Pour célébrer cette arrivée et souligner les avantages de ce nouvel environnement, autant que pour signifier l'importance scientifique et symbolique de la convention de services reliant l'IFHA et son université d'accueil dans une année dédiée à la commémoration du cinquantième anniversaire de la signature du traité de l'Elysée en 1963, une cérémonie s'est tenue le 19 avril 2013 en présence de 150 personnalités scientifiques et politiques françaises et allemandes. Les orateurs, parmi lesquels le professeur Werner Müller-Esterl, président en exercice de l'université de Francfort, Madame Zsusza Breier, Secrétaire d'Etat aux affaires européennes du Land de Hesse, l'ambassadeur de France en Allemagne, représenté par le conseiller culturel en poste, Monsieur Emmanuel Suard, ont souligné l'importance pour la relation francoallemande, et au-delà pour le commerce des idées en Europe, de la présence d'institutions universitaires et académiques dans chacun des pays afin de favoriser l'analyse en commun des phénomènes historiques de longue durée et de leurs impacts sur les sociétés contemporaines ainsi que pour accompagner et amplifier la mobilité académique et scientifique des étudiants et des jeunes chercheurs. À leur tour, la Ministre-Présidente de la Sarre et Plénipotentiaire de la République Fédérale d'Allemagne pour la coopération franco-allemande, Madame Annegret KrampKarrenbauer, et les deux présidents des conférences d'universités françaises et allemandes, Monsieur Jean-Pierre Finance représentant la partie française, et le recteur Horst Hippler, ont tenu à souligner par leurs exposés, articulés autour de la question de la construction d'un avenir commun pour les universités françaises et allemandes en Europe, le rôle central que les institutions de recherche immergées dans des 
établissements universitaires étaient appelées à jouer en terme de formation d'une génération intellectuelle de jeunes cadres chargés d'animer demain la relation francoallemande dans tous les domaines.

\section{AUTEUR}

\section{PIERRE MONNET}

IFHA, Francfort-sur-le-Main 